\title{
How to Humanize Technology in Smart Cities
}

Zvi Weinstein, Israel Smart Cities Institute, Israel

\begin{abstract}
The article describes a personal point of view on the relationships between technology innovations in smart cities and how they are used for the benefits of the residents. Are they technologically or humanly characterized? Are we able to humanize technology for the need of the residents? Addressing my point of view, first of all, I have to confess that I belong to the " $x$ " generation and therefore a gap divides me from updated technologies that are born almost every minute around the globe. Second, this is not a research paper or data analysis. Third, an additional set of questions will focus on the direction/s technology is pushing the interfaces with city residents. The paper argues that citizencentered humanized approach for the future of smart cities is needed for shifting technology- centered to human and social considerations
\end{abstract}

\section{KEYWORDS}

Generations of Technology, Humanizing Technology, Smart City, Society, Using Technology in Smart City

\section{FORWARD}

I have decided to write down this article, because I feel it touches hundreds of thousands of people around the world who do not have the opportunity to activate their voice in front of decision makers in different levels of government, as well as public and private companies to emphasis the human and social aspects of technologies for our daily uses.

I learnt, that the major parts of technological innovations are not used by ordinary people residents of urban settlements but they serve governments, big companies and local municipalities. They create and design big volumes of data which need to be managed by special analytics experts targeted to be used by their customers. Technologies aiming to be used by people who are the customers of the city services belong whether they are the elderly or the younger generation or those who haves and those who have not.

For me, as one who begin his eighth life-time decade the attitude towards sophisticated technology like Internet of Things (IOT), Block-Chain, Artificial Intelligence (AI), Augmented Reality (AR), 5G and many others advanced ones, doesn't say much. As a human being who live in the urban arena, I' $m$ surrounded with issues of mobility, transportation, circular economy, access to services, governance, citizen participation, citizen science all of which deal with high technology and big data inputs.

Based on my experiences as an urban citizen, my conclusion is that we have to treat technology as an enabler and focus on citizens and society as a whole. Smart city operation for me means citizens 
that ripe the rewards. It's all about people and setting up the right governance to offer the highest level of civic services.

I'm asking myself difficult questions, with no sufficient answers: What are the problems people are facing and cope with towards technology of all sort? Is it the modern language used by technology? Is it the social, educational cultural and environmental backgrounds that cause us to stay behind the fast runners? How might technologies help and assist us to cope and address these problems? How could we make use of new technologies that are introduced into urban smart cities for our human benefits? How emerging technology can play a positive role related to societal challenges?

A note about methodology: The sources for the paper are based on the author experiences and open discussions publicly made with few dozen people of both genders similar to my age. They live in different locations (big cities, periphery, different socio-economic status and occupations). The search for written references dealing with humanizing technology is unfortunately limited. Most of it were articles and few chapters or paragraphs in books. Somehow, the written information neglects in most cases any relation to people in society who are the natural customers of technology. I have chosen to present examples of several Israeli cities that enhance human technologies. Therefore, it is a descriptive and qualitative and not a quantitative and data analysis paper. At the end of the paper a list of key terms definitions is found on page 19.

\section{INTRODUCTION}

We are living in an era where most of our daily decisions are led by technology and digitization which are ubiquitous in our society. It penetrates every aspect of our lives: the technology is used in medical operations and treatments; we use it as a social media to build connections among people; big data techniques collect information about us and our emotion recognition; and it tries to use our daily language and transfer it into robots, machines and artificial intelligence to replace human beings in various daily activities.

The growing use of information and communication technology (ICT) means that people's connectivity both within themselves and between outside institutions is done in many cases through augmented and virtual reality that use digital platforms. In other words, technology platforms are changing paradigms around us and new concepts challenge our society, culture and behavior. Big volumes of our daily lives activities are done in the digitization way such as consumption, shopping, banking transaction, contacting people, friends and family (Barby, 2012; Peppet, 2014; Royakkers et.al., 2018). On the other side, these technological developments raise big issues of morals, ethics and regulations. Due to the short space of the paper we cannot widen the discussion on these issues.

Smart cities are appearing everywhere based on new innovations devices adopted and implemented. This tendency is speeding and causing competition among cities to achieve the award of smarter than others. Many are aware that the term smart city became a buzz word and a new term has to replace it. The focus should be the citizens in the cities and how they are going to use and benefit from technological developments. The disruptive technologies like block-chain, crypto-money, processes of robotic unites, drones and automation mobility are going to change human set of values and paradigms in the next coming years. And the question we ask is how will it change the behavior of urban citizens and their daily life?

Moffit (2018) has published the Top 30 Technologies 2018-2023 (Figure 1).

These topping technologies list such as Artificial Intelligence, Internet of Things, Mobile/Social Internet, Bloch Chain, Big Data and Automation and closes with Better, Faster Internet, Proximity Tech and New Screens intend to cause deep changes and impacts on how and where we live. These technologies are led by the industry and big companies. And we ask: will they be used by citizens for their quality of life benefits? How these new technologies are going to change everyone attitude and behavior at the work place, family framework, open spaces, local and central governments and more? These questions will remain for public and stakeholder open discussions. 
Figure 1. The 30 technologies of the next decade. Source: Moffit, S. Wikibrand.com.

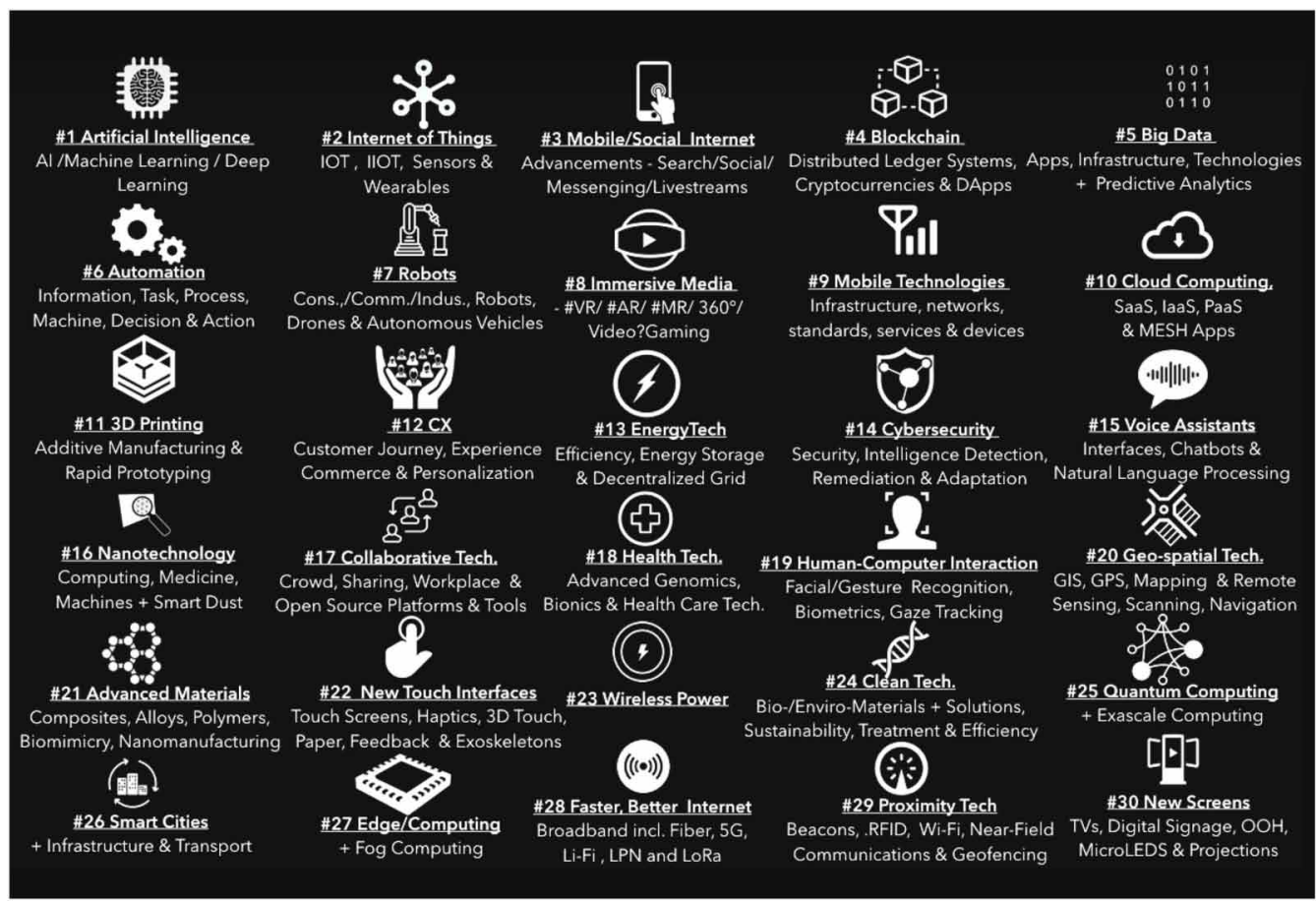

For ordinary citizen smart technologies have to be able to give adaptable answers to fill their needs and to deliver equal and equitable solutions to different populations who live in the urban framework. The involvement of private companies and the preference of development are stemmed from interests of capital might lead to the exclusion of existing populations by means of cultivating strong populations living in the city and encouraging processes of delivering higher standards of living into down towns to start a gentrification process.

For the last twenty years most of the cities around the globe began to invest huge amounts of money to become "smart" using high-tech technologies pushed by leading international companies such as Cisco, Microsoft, IBM and later on by Alibaba, Amazon and others. These technologies were adopted by local governments mainly in the physical infrastructures of the city such as water, transportation, street lighting, parking, street security, big data, internet of things, artificial intelligence, block chain, cyber security, data analysis and the list go on. These technologies didn't take much consideration to invite citizens to be an active part of the innovations.

In the last decade the concept that sees the smart city model a mean to strengthen civic and public participation of citizens in the government networks, is called now smart e-governance (Robinson, 2015). It is a governance structure in which the technology is assimilated in it and enable direct communication with the citizens. In its essence the term "smart governance" is focused in the ability to use information and communication technologies as a mean to directly empower the connection with the citizen and to enable new forms of participation and engagement of city inhabitants in the processes and mechanisms of the local or central government. According to this approach the spatial digitization is said to supply the citizens a fast, direct and updated information, and thus to intensify the transparency and awareness of local community to its environment where he/she lives (Hatuka, 2018).

Smart governance is based on four main pillars: 
- Access and use of information: Today, democratic regimes are able to let more citizens to participate in the development of civic-technology in the process of building the "smart" city by minimizing the existed blocks preventing the entrance to the market;

- Public engagement: Developing technologies to civic involvement in order to enable and advance wide democratic basis of participation (Shkabatur in Hatuka, 2018:17). The idea is that citizens will be able to engage others through crowdsourcing platforms (Twitter, Facebook, Instagram and WhatsApp);

- Optimal management: The assumption that access to big data will support policy makers to accept better decisions is based on the narrative that private companies advance regarding the utopic smart city vision. On the other hand, there are researches who criticize the way data is collected and insist that it has to be part of public-political debate;

- Servicity: Information communication technology supplies variety of auxiliary means: smart water and electricity meters, indoor and outdoor lighting, traffic signals, navigation networks, cellular instruments and many more. These technologies contribute to improve services but cause citizens to sacrifice their privacy, information secure and their freedom of choice.

The big question is who has the complete information and knowledge to decide on a policy that serve urban citizens to fulfill their needs?

As far as the literature advices, the answers to the above and other questions this paper raises are still under arguments, debates and discussions with different theories and stakeholders in a way of trails and errors. Time is needed to absorb the influences of technology and making the right considerations especially those related to urban citizens whose city is going under deep changes to become a smart city.

There is a wide agreement that the rapid development of digital technologies is drastically influencing everyday life of citizens, changing behavior of consumption and personal choices of priority. Castells (2004) stated that digitation has a broad spectrum of influences on the knowledge, human culture, social structure and thought. All are finding expressions in the smart urban life.

The urban environment is increasingly conceptualized as a complex techno-social network. The city exists when it is occupied by a sustained stream of people. In this sense people are the core of the city. Individuals concurrently exist as constitutive nodes, users and customers of the smart city.

We rely on technology for long centuries to manage our lives and that fact set to stay for many years to follow. Yet, as our lives become increasingly entwined with technology, we will notice a shift: Technology will continue to evolve to meet our human needs.

The famous scientist Albert Einstein once wrote: "It has become appallingly obvious that our technology has exceeded our humanity [...] Concern for man himself and his fate must always form the chief interest of all technical endeavor. Never forget this in the midst of your diagram and equations."

Einstein was right. Technological solutions keep on developing straight to our everyday life in smart cities which makes providers wonder: How can we humanize technology? And by what means we can enable more space to the human actor integrate it to the innovation in a data rich world of technologies invented, created, designed and marketed with no limits on global scale?

Today's technology is making feel the discomfort and dissonance that comes with being out of balance that this unrelenting focus on technology advancement is somehow leaving us behind. Humans experience the world through our five sense. Machines do not. And that is why we see the evolution of technology devices and apps increasingly attempting to communicate with us the way that we know how.

\section{HUMANIZED TECHNOLOGY PARADIGMS}

The paper will use the following citations, paradigms / statements as its main background points to describe and discuss the issue of how to humanize technology in smart city: 
1. Technology is just an enabler tool, not the goal. And as such it is only useful as long as the person uses it (Ferrer Escoda, 2015);

2. "Cities have the capability of providing something for everybody only because and only when they are created by everybody" (Jean Jacobs, 1961);

3. "A smart city cannot be for the citizens if it doesn't serve its human purposes. You can have the best technology but if it doesn't take into consideration the comfort of a human being, it is not smart" (Dr. Talal Abu Ghazaleh, 2012);

4. "If democracy is about the will of the people than it's our job to find out what that will be" (George Gallup, 2017);

5. "It isn't the faith in Machines it's the faith in people" (Steve Jobs, Apple).

These citations look very simple and understandable but in reality, they are far away from being implemented as a standard and a commitment policy of local governments.

Cities who wish to become "smart cities" are driven by technology providers to achieve their economic, environmental and social goals. Technology provides the ability to deliver city services with greater efficiency and effectiveness. This combined with the focus on the end user is at the heart of the smart city and focus on creating a more connected, more intuitive, safer, more mobile, sustainable and ultimately more attractive urban experience. Utilizing technology among cities became an official strategy to initiate top-down decisions to win the title "smart city". This approach didn't always assured success and it began to change its way using drivers of collaboration and participation to foster and empower citizen or human-centric approaches.

For cities to truly realize the benefits of smart city initiatives they must embrace a bottom-up approach or risk wasting precious resources and expanding political capital for limited returns. A bottom -up approach means being intentional about systematically incorporating citizen voice throughout a smart cities project lifecycle. This is needed to help move urban residents from passive consumers to engaged consumers. This trend will continue to rise as urban citizens are demanding more flexible, personalized services.

\section{DEVELOPMENTS IN HUMAN-CENTERED APPROACHES}

Boyd Cohen (2015) in his article The 3 Generation of Smart Cities described their evolutions and characteristics:

Smart cities phase 1: Smart cities are led by major technology companies to enhance multi innovations among local government departments.

Smart cities phase 2: Local governments are utilizing different technologies to enable investments aimed at improving quality of life.

Smart cities phase 3: Smart cities approach is changed from technology-centric vision to citizen/ human-centric vision. It is characterized by co-creation and partnership.

These phases describe smart cities stages well organized: a city needs to pass these three stages in order to complete full technology process which enables the creation of close relationships with its citizens not just as customers but as a significant stakeholder partners in the process of decisionmaking policy.

The third stage is the point where we can be assured that technology begins its transformation from pure one to a human one. That because technology becomes more accessible to wider and diverse populations living in the city. Technology becomes accustomed to many citizens who are using ICT and other types of technology tools to influence decision makers at the local government level. 
It seems there is a parallel advancement between the growth of urbanism and the use of technology innovations in the city. The wave of urbanism growth since the 1950's when cities composed only $29 \%$ of the world population while in 2014 the figure doubled to $54 \%$ and the estimation of the UN to 2050 will reach $66 \%$ (UN, 2012). Cities who want to supply high level of services to their population must establish effective and efficient infrastructures to serve their citizens. The way to achieve it is through smart technological innovations, learning skills and experiences, education, developing citizens-based and centric applications and social capital to enable free accessible and use of local government data base by all their residents including those vulnerable and marginalized populations.

More and more commentators today critique the establishment hegemony of the technologycentric epistemology embedded in any one proprietary smart city vision (Fort et al., 2015). There is a growing recognition amongst smart cities practitioners as well as stakeholders and local governments policy maker leaders that a shift is required from technology-centered to human-centered to build partnerships with local citizens using resources such as social innovation and sharing economy, open database and transparency. Another factor that brings cities and citizens together is the emergence of big data.

There are different means and trends to close the gaps between top-down policy and bottom-up citizen centric regarding the issue how to humanize technology. From the local government perspective, citizen engagement is seen as a fundamental part of democracy, and in regard to smart city the role of the officials is to set standards for using data and privacy for the citizens.

As long as new technology is developed, active engagement of citizens should re-examine evidence from experiments in co-creation and collaboration design. Information and Communication Technologies are adding new dimensions to the roles attributed to citizens and communities, both in terms of passive opportunities, for instance the measuring of behavior through data points, or active involvement through usage of platform modules and the active community building. New techniques for citizen engagement are found among hubs and accelerators and urban labs where ordinary citizens are testing new innovations and practices to be implemented in the daily life of the city residents to improve their quality of life (Costa et al., 2018).

A report by the European Union (2016) overviewed key methods and approaches analyzing the potential for wide scale roll out of integrated smart cities and communities solutions. They are briefly summarized below:

1. Technological innovations allow for new and diverse forms of participation and therefore the co-developing of city solutions. Particularly relevant are applications that permit new ways of collecting data, gathering feedback, democratizing decision-making and creating built-in sustainability of solutions by creating community ownership. Examples include: Integrated planning procedures; Participatory budgeting; Idea banks and online deliberation and decision making; Co-design set ups often as intermediary agencies that facilitate co-design between citizens and public authorities;

2. Crowdsourcing takes place when the public provide information or means. The key features of this model are that it is online, open and distributed. Collective intelligence of the crowd can be harnessed and brought together to achieve behavioral change or to tackle pressing social challenges as a community. Examples include: Citizen led issues reporting or the contribution of citizen data; Crowdsourcing data initiatives; Crowdfunding;

3. City centers and neighborhoods increasingly exhibit a number of district level innovation spaces such as large-scale demonstrators, living labs or smart streets which are ideal platform to explore the needs of users as residents and citizens. Examples include communal yards; open public spaces; and daycare services;

4. Community-driven innovation in cities can have many facets. It can be innovation owned and driven by a community platform application supported by mobile technologies such as sharing 
economy services. Examples include: co-operative governance structures; grassroots community projects; and community-based business models.

Many other organizations within the European Union, just to mention few: EIP-SCC (European Innovation Partnership on Smart Cities and Communities, 2015); Smarter Together (Smart and inclusive Solutions for a Better Life in Urban Districts); Smart Cities Connect, 2018; and Meeting of the Mind 2017, 2018 have all very similar approaches and suggestions to find solutions for the issues of smart cities and their citizens.

\section{THREATS AND NEGATIVE ASPECTS OF TECHNOLOGICAL}

It is unavoidable in this paper not to briefly mention the "bad" influences and effects of technology on human beings. Part of the interface between human beings and technology is its negative influences on society. Although technological innovations aim to bring efficient, effective and widespread uses, it causes to interaction difficulties and loneliness. In this case it is worthwhile to mention Tracey Crouch who was appointed as London's Minister of Loneliness. In Britain, more than 9 million people report feeling isolated. This is a societal conundrum. City population are growing while technology keeps us increasingly connected. So physically and digitally we are closer together than ever before. But still people of all ages - especially young adults - are experiencing solitude and sadness (Collier, 2019).

One well-known threat is upon our personal privacy which is considered as our holy exterritorial right. Technology companies such as Google and Facebook are collecting a lot of information about each of us who is connected and make use of their applications. They are using algorithms to analyze your tests, priorities, consuming, field of interests and thus directed their own advertisement or third party to your mailbox when it is just a spam.

Another treat is the technologies using automation which treat employees who are afraid to be replaced by robots, machines and autonomous cars. In addition, the rapid technological innovations cause people to adapt themselves to the new occupations and opportunities provided by technology. Sometimes, it causes even unemployment and loss of income with all its social, economic, psychological effects on the human being.

Some issues even raise the question of the value of technology if it does not help to make cities more inclusive and responsive to people and in addition, evoke citizen engagement. Society is not homogeneous. It is divided between those who have the access to resources and those who have not, usually the poor, the elderly and the marginalized sectors of society. The last ones are disconnected to the main central stream of users, due to lack of access to Information and Communication Technology (ICT), low level of education, financial resources, and living conditions.

Therefore, technology cannot be isolated from the social spheres and influences. It must be regarded as a tool, facilitator and an enabler for sustained quality of life of urban citizens with no difference of gender, education, religion, occupation, etc.

Smaniotto Costa $(2018$, p. 9) argues that the cyber parks identify the technology as a great enabler for engaging with people, recognizes also the technology alone is never the solution. Therefore, it cannot replace the social capital of cohesion, mental and physical activities among human beings.

Another aspect of negative effects is the digital exclusion and inequalities created in many cities due to the urban complexity structures of social, economic and environmental elements. This point will be discussed in the next section.

\section{SOCIAL EXCLUSION AND INEQUALITIES IN SMART CITY}

Technology has two faces: face one enables to limit social gaps because it enables accessing to education and information. On the contrary, face two might lead to growing gaps due to lack of 
infrastructure and lack of digitization skills. In a city where variety of populations live, the gaps are connected to the social characteristics of the different groups (Hatuka, 2018).

In the mid of the 1990's the awareness to inequality among social groups in relation to technological accessibility and uses was termed digital gap. Today we live in another reality where many have access to wide range of instruments - smartphone, computer, cellular connection - and it is difficult to point out on absolute inequality between who is included and who is excluded and it is possible to define a relative inequality (Weinstein, 2007).

The research on digital inequalities in the world shows, that social-economic and cognitive abilities influence the way internet is used (Robinson et al., 2015). In a research conducted among teenagers from four different cities (Hannover, Lisbon, Volos, and Tel Aviv), to provide insights on their perspectives and on their ICT practices we found out that teenagers as Digital Natives belong to the "Z" generation, a generation born completely within the technological age having true global culture with quite uniform characteristics (Weinstein et al., 2018).

That said, it is almost natural that ICTs scored very high in the preferences of teenagers interviewed. If there are any differences among them, these should be attributed to the local conditions in each country, the standards of living, differences in education, culture, degree of ICTs penetration and provision of quality public spaces.

In 2017, the OECD warned that while digitization could improve services and address global/ local challenges ranging from the environment to health and from transport to governance, it could also accentuate inequalities (OECD, 2017). According to the World Bank, the lack of broadly available digital infrastructure (terrestrial of fixed and mobile broadband) and the cost of widespread access to the internet are magnifying the digital divide and the slow uptake of smarter cities applications in the developing world (Birch et al., 2018).

\section{ISRAELI INITIATIVES ENHANCING INEQUALITY SOLUTIONS}

I'm proud to present innovative initiatives implemented by Israeli cities to show how to cope with technological inequalities as it is done among the Israeli society. The central government in Israel together with the Digital Israel Office and the Israeli Innovation Authority focus in the gaps and inequalities that exists among different cities. The tension between the local the urban and the regional spheres are the most important in the state of Israel which is characterized in deep gaps between the center and the periphery and in some cases even between two adjacent cities. There are 257 local municipalities in Israel with a population of 9 million inhabitants. They are significantly differed from each other in respect to their management abilities, human capital, resources, budgets, needs and challenges to keep and achieve. In regard to digital domain there are localities that invest to become smart city and others that even did not begin the process (CBS, 2019).

The social initiatives of six leading Israeli cities will be described below. They all have reference to equal opportunities and inequalities. One of them-Tel Aviv-will be mentioned in detail since it is the only one that won the world award at Smart City Expo World Congress in Barcelona in 2014 and its application is implemented by many cities around the globe like India.

- City of Hertzliya: Accelerator for urban technological enterprises. The aim is to use such a platform to supply opportunity to the whole population in the city. The project tries to bring together unique resources the city has - the close connections with the business and the technology sectors located in the city, hi-tech employees who live in the city and citizens who are interested to grow in that field.

In this initiative the municipality position is to act as a mediator that connect stakeholders and recruit resources that are not materials to establish a hub for urban technology enterprises. The 
production of the innovations is examined and tested by different departments of the municipality and implemented within them. It saves the local municipality money, time and improve the services given to the citizens.

- City of Rishon Le-Tzion: The need to enter technology into the municipality departments was felt specially with the process of enrolling children to kindergartens among some neighborhoods of the city whom their accessibility to on-line enrolling connection was very low in using an internet. In addition, residents of these neighborhoods had a mistrust issue conflict towards the local municipality, and they used to come personally to the city hall and watch that their children are being registered.

There was an idea to connect the residents of those neighborhoods to the internet but the high costs of building WI-FI infrastructure dropped down the idea. Instead, the municipality decided to connect all schools to internet services through optic fibers to enable students to learn through computers. Due to the fact that schools are public goods, the city took the decision to digitized all of them.

- City of Jerusalem: The city which is the biggest one in Israel (about 950,000 inhabitants), reveals deep gaps among all its neighborhoods and regions. The main issue policy makers are coping with is the many different multi-cultural groups that live in the city and how to fit it to the need of those populations whether they are Orthodox, Arabs, other religion groups and seculars.

Thus, the municipality removed all parking-meter along the streets of the city and decided to use only parking applications. This decision caused a problem since not all Orthodox people are using smartphones due to requirement put on by the Rabanic authorities. The solution came when proper smartphones found to be proved as "Kosher" ones for technological uses.

- City of Beer Sheva: The city was chosen by the Israeli Government to be the first digital city. The municipality is enhancing a pilot with the Ministry of Education and the Headquarter of Digital Israel collaboration to adjust the education network for the digital era.

In addition, the city is advancing a think-tank team to improve welfare services through technologies specially for those who are dependent on the Welfare services. The aim of the city is to organize a digital array where all suppliers of welfare services work on the same platform. On the strategic level of the city it supplies welfare and education services to all its citizens. The most important point is the focus on the service accessibility point of view and not how much money is saved.

- City of Eilat: Today, $70 \%$ of electricity supply to the city of Eilat comes from solar panels. It is expected that in a period of five years the city will be able to supply electricity needs to all households and will save three million Euros each year. The city aim is to bring a solar revolution and use only renewable energy. It encouraged households to use solar panels on the buildings roofs and thus to save much for their expenses which are very high due to the climate conditions of the desert in this most southern city in Israel.

In response to residents with technological infrastructure access problems, the city hall established a professional team of municipality employees who visit personally the handicapped, the elderly and the new immigrants to give them all services they need face-to-face. 


\section{DIGI-TEL AS A TOOL TO HUMANIZED TECHNOLOGY}

As an example of how to humanize technology, we have chosen to briefly present here the example of digital transformation from technology driven to citizen-centric engagement as it is activated by Tel Aviv Municipality, Israel. It is known as Digi-Tel, a personalized digital communications network technology to connect the city of Tel Aviv with its citizens. Tel Aviv won the international award of the Smart City World Expo Conference in Barcelona in 2014 leading the topic of "Cities for Citizens and Citizens for Cities" (Weinstein, 2017).

Digi-Tel aims to engage, involve and connect city residents directly to municipal departments, and enable them to benefit from the efficient two ways use of information and communication technology. Today, $86 \%$ of Tel Aviv inhabitants (370,000 out of 440,000) are eligible to register as members of Digi-Tel and to enjoy its benefits. As such, Digi-Tel delivers updated information in a variety of domains, providing municipal services, encouraging residents' engagement, transparency and mobility, with the aim to improve their quality of life. As a personalized card it delivers to each resident the exact information he/she describes when filling Digi-Tel form where you point out your preferences such as community events, citizen participation, sport events, open spaces performances, activities for kids (the Digi-Kid card) as well as for elderly people. There are specific cards like the Digi-Dog aimed at animals' owners and the Digi-Soldiers for residents who are at their army service. The municipality offers hundreds of activities for the benefit of all ages, neighborhoods, tourists as well as visitors.

Digi-Tel composes of three elements - The people (citizens and visitors), a friendly city (quality of life) and data (technology). These elements are integrated in the city's vision to create a city for all its citizens. The local government promotes a policy of transparency of the information provided to the general public, enabling residents to access the municipality database on one hand and encouraging citizens to proactively engage the municipality, while additionally reporting on events, activities and concerns on the other hand.

The involvement of ordinary citizens in knowledge production and creation places in the city of Tel Aviv has passed four stages: Stage one: Local government of Tel Aviv establish effective and efficient new type of organizational structure focused on service as culture to its citizens accepted as local political commitment; Stage two: Top-down policy of increasing transparency and enhancing participatory democracy; Stage three: The stage of bottom-up where the creation of Digi-Tel tool enabling the dialogue between local citizens and all municipality departments; Stage four: The citizen to citizen infrastructure which aims to create and enables better well-being conditions for the benefit of local citizens in their neighborhoods among themselves and to build strong communities.

Digi-Tel became a model of replication for many cities around the world. The leadership of Tel Aviv understood that the core of the city is its citizens who live, work, study, visit and use local services. Their diverse structure and culture build the social fabric of the city, and therefore all invested efforts should be directed towards their benefits.

Hatuka (2018, p. 112) propose five policy recommendations to cope with digital inequalities:

- Examining and analyzing an initiative and technology implementation regarding the social groups which composed the city. It will map the compliance of different groups to use on-line services;

- Developing targeted strategies of social influence with focus on technology. In this way, an opportunity to limit the digitization gaps and focusing on resources division of participation, accessibility and education will be achieved;

- Compensation for companies for adopting holistic digital planning principles. Local municipalities have to prefer initiatives that enhance social inclusion, various groups of population who are in need. The same is in case of product developing which take into account social aspects like language adjustment and design and access to different population compositions; 
- Creation of supporting community network to develop and strengthen information and communication technologies. The aim is to assimilate technology among all citizens with emphasis on technological education. This has to be built as an inclusive and holistic ecosystem where community institutions are the places to take over the responsibility and teach digital skills;

- Creation of social mobility through digital skills. The information communication technology gaps are a spectrum of many users with various differences in their socio-economic backgrounds that prevent them from achieving advanced skills to find better jobs and occupations.

Given the descriptions above, the question raised is how to overcome the conflicts between human vis-versa machine and technology? To answer it, we will use the term "social technology" and its implications on people in a digital environment.

\section{SOCIAL TECHNOLOGIES}

The concept of social technologies had rooted itself in various disciplines of science in recent decades. We describe here several definitions by researchers as well as by organizations to show the wide spectrum the term is used.

The term "social technology" is defined as a set of potentially arbitrary effective social challenges refillable solution, ways to achieve the intended results, doing social impact of human, social groups, different social structures behavior (Bugin et al., 2010). McKinsey Global Institute (2012) defines social technologies as digital technologies used by people to interact socially and together to create, enhance and exchange content. Social technologies are an interdisciplinary field, which focuses on applying information communication and emerging technologies to serve the goal of society. It means, those technical innovations, which represent progressive developments. Almost any digital technology can be made "social" through adding the ability for people to connect, comment or share.

Social technologies distinguish themselves through the following three characteristics (Bugin et al., 2012, pp. 1-10):

- "are enabled by information technology"

- "provide distributed rights to create. Add, and/or modify content and communication"

- "enable distributed access to consume content and communication"

Social technologies include a wide range of various technological instruments, or as an interaction tool between them. They include many of the technologies that are classified as "social media", "web 3.0" and "collaboration tools". The diagram in Figure 2, describes the range of social collaboration and technologies in three sectors - government, community and business.

It can be concluded that the current function of social technology is for social purposes via digital means. At its most narrow sense, social technologies can be understood as information and communication tools that have a range of economic, social, cultural or other public life processes available to each person: computers, smart phones, social networks, internet etc. (Skarzauskiene, 2015).

Social technologies unleash creative forces among users and enable new relationships and group dynamics. In the hyperactive world, people can feel immediate benefits in connecting with the right peers, getting answers to questions and finding information. The Millennials also known as the Millennial Generation (Generation Y), are people born between 1980 and 2000. Social technologies are becoming the preferred method of communication of the new generation.

Social technologies have the potential to affect positive change in communities and governments. Such technologies can be disruptive to established corporate and governmental power structures as happened, for instance, during the Arab Spring 2011, and during the Social Protest in summer 2011-2012 in Israel. The use of technologies enables individuals to connect on a different scale and 
Figure 2. Social collaboration tools of technologies (Skarzauskiene, Tamosiunaite, and Zaleniene, 2013)

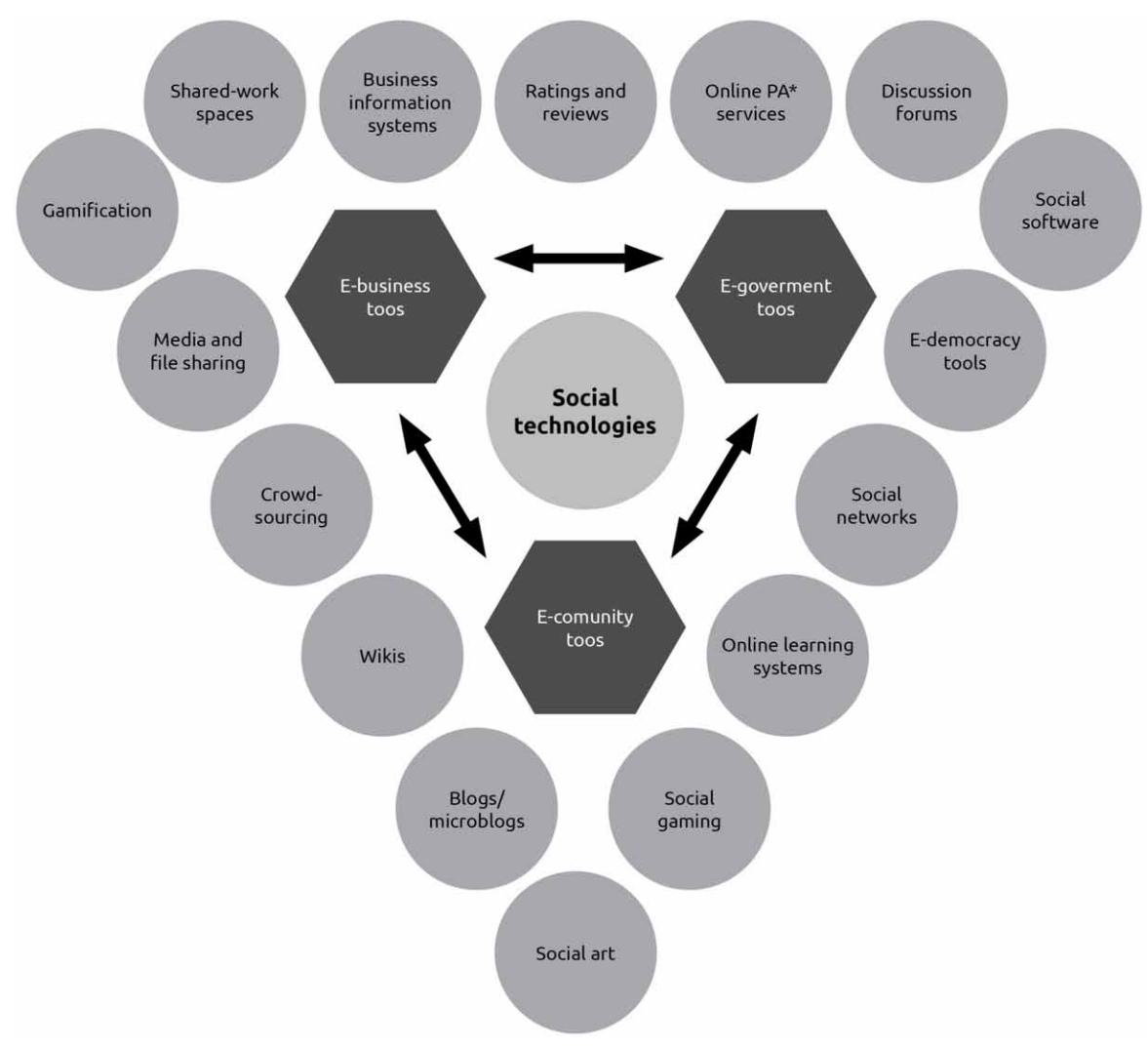

to create unified, powerful voice acting as consumers or entire societies that can have a compelling impact on dialogues with corporations and governments.

Old generation tend to be more skeptical about social technologies. Therefore, it is important to implement something useful to monitor the user engagement and to educate the community about using social technologies by means of face-to-face interactions that are critical to producing genuine breakthrough.

Social technologies should be perceived as tools to unify the wealth of interests and intentions of the units of a social structure in order to use the internal features of a social community as efficiently as possible.

Skarzauskiene (2015) argues, that thus, social technologies can be seen as an intervention means to affect the social elements of societal structures. A clear declaration of the aim, the achievement of which can be facilitated by such intervention, is the major criterion enabling to call the technology, which in one way or another affects social processes, a social technology.

Technological advancements broaden the possibilities for "technologizing" the management and organization of complex structures rejecting the hierarchical model. Social networks, means of public debates, social publicizing, social marketing, systems of artificial intelligence, virtual world, legislation information and other technologies which are capable of forming and online community and collective intelligence can be used as a political and administrative technique, a technique that can become an important part in optimizing the management of a multicultural network society. 


\section{CONCLUSION}

The paper shows that it is difficult to separate between human beings and technology. From a technology perspective, the rapid and continuous digital development poses a continuous challenge to those interested in the nexus people, places and technologies. We cannot stop changes, we can try to understand these and inform and educate people, no matter to which peer group they belong, and especially in a co-creation production of more inclusive and responsive societies.

Collective intelligence as part of social technologies is the most relevant success factor for becoming smart. Being smart builds on the human capacity as a sum of individual actors in a community that enables the creation and adoption of solutions, leading to an efficient transformation of the community by a strong smart city solutions ecosystem.

Humanizing technology should be about advancing humanity using technology as a mean. There is still no defined and absolute answer to the question if artificial intelligence will be the natural language processing and understanding the question and be able to generate response.

We will conclude with George Gallup words: "If democracy is about the will of the people than it's our job (the technological inventors and developers) to find out what that will be."

People and technology are the most vibrant engines of smart cities to cause the transparency revolution to humanize technology for the benefits, wellbeing and improved quality of life in the cities around the world. Technology provides the ability to deliver city services with greater efficiency and effectiveness. This combined with the focus on the end user - the citizen - creates more connected networks of local government and citizens. Smart cities are not merely the aggregation of sensors, boxes with blinked lights and fiber-optic cables. People in cities are the beginning and the end of the smart urban debate (Araya, 2015).

Barcelona Smart City 5.0 (2015) considers technology as a tool enabling: For better decisions and policy-making; More efficient resource allocation; Citizen and stakeholder empowerment; More open, transparent and participatory.

Opportunity to do things differently in a smarter way.

Smart cities and their citizens become more connected and better served with technology. And as a conclusion we can argue the closeness of people and their social, intellectual, educational and human capitals to the systems and networks that design the technological tools are the keys for achieving the purpose of Humanizing Technology. Technology stops to be exclusively at the hands of local government and stakeholder decision makers and is widely used by citizens of smart cities to improve their quality of life. This is the greatest achievement of citizen transforming top-down approach of local government officials' policy to bottom-up approach expressed by co-creation, co-production, co-design partnerships of smart cities citizens. The values of smart city technologies must be a significant part of the conversation. If we wish to develop truly humane cities, we must encourage systems and technologies that give voice to the people and communities who make and remake the city every day.

To sum up, here are motivation and practical ideas to be activated in smart cities as triggers to policy makers sitting at the significant nodes of decision making and taking into consideration the benefits for their citizens:

1. Finding, using and implementing the benefits of advanced data analysis, artificial intelligence and algorithms by bringing them more directly and closely with every city department employee;

2. Improving quality of life in systems of water, energy, healthcare, consumption;

3. Local governments have to fix strategic objectives regarding artificial intelligence issue to bring change to smart city to a personalized adventure and will open many possibilities to improve urban processes to all its citizens;

4. The humanize approach of technology has to become smart cities' addressing function to shift social inequalities, prejudice and discrimination into equity, ethics and democratic society; 
5. Technology develops in an exponential computing but it is not free or accessible to everyone. Therefore, in order to emphasise and achieve co-creation, co-design, collaboration and corporation among different stakeholders we call social sciences, policy makers, entrepreneurs, local leaders, academia and industry to monitor practical results;

6. Humanize technological systems means to generate and engage more human relationships between people and devices in efficient ways. This can be achieved by artificial intelligence and people-centered design as key elements for the humanization of technology;

7. Technology is not an end unto itself. Technology is a means to this end, an enabler of better community;

8. Using artificial intelligence, machines and systems enable to learn from the experience of each individual to improve the responses in the future. Artificial intelligence and people-centered design are the key elements for the humanization of technology (Slash Team, 2018).

The main impact results in a new approach to understand, create, design and implement strategic objectives of humanizing technology among smart cities complexes. It will realize a think tank to assure equal access to poor and needed population considering social-economic-environmental aspects. 


\section{REFERENCES}

Araya, D. (2015). Smart Cities as Democratic Ecologies. New York: Palgrave Macmillan. doi:10.1057/9781137377203

Barby, E. (2012). The internet of things, legal aspects: What will change (everything). Communications \& Strategies, 87(3), 83-100.

Birch, E., Voith, R., \& Wacher, S. (2018). Can Rapidly Urbanized Cities in Low and Moderate Income Countries Become Smarter? Penn University.

Castells, M. (2004). The Power of Identity the Information Age: Economy, Society and Culture (Vol. II). Oxford: Blackwell.

Central Bureau of Statistics. (2019). Annual Statistics for Israel. State of Israel.

Cohen, B. (2013). 3 Generation of Smart Cities. Urenio.org.

Collier, C. (2019, May 14). Lonely people in big cities: How technology is both creating and solving the isolation crisis. Smart Cities Connect.

Costa, C. S., Erjavec, I. Š., Kenna, T., De Lange, M., Ioannidis, K., Maksymiuk, G., \& De Waal, M. (Eds.). (2019). CyberParks-The Interface Between People, Places and Technology: New Approaches and Perspectives. Springer.

EIP- Smart cities and Communities. (2015). Retrieved from http://eu-smartcities.eu

European Commission. (2016). Analyzing the Potential for wide Scale Roll-Out of Integrated Smart Cities and Communities solutions. The role of citizens in creating sustainable integrated SCC solutions.

Ferrer Escoda, J. R. (2015, June). Barcelona 5.0 Smart City Governance Model. Presentation at Major Cities of Europe Conference 2015. Academic Press.

Foth, M., Brynskov, M., \& Timo, O. (Eds.). (2015). Citizen's right to the digital city: Urban interfaces, activism, and place making. Springer.

George Gallup. (2017). Gallup World Poll.

Ghazaleh; T.A. (2012). Information and Communication Technology (ICT) in education in Five Arab states. Unesco and Tag-ORG.

Hatuka, T. (Ed.). (2018). The Digital City. Planning, technology, privacy and inequality. Tel Aviv University. (in Hebrew).

Bughin, J., Byers, A. H., \& Chui, M. (2011). How Social Technologies are Extending the Organization. The McKinsey Quarterly, 20(11), 1-10.

Jacobs, J. (1961). The Death and Life of Great American cities. Random House Inc.

James, J. \& Stoppenhagen. S. (2016, October 17). Smart cities Best Partners. Meeting of the Mind.

Marluci, M. Paschalis. A., Smaniotto Costa. C., \& Weinstein. Z. (2018). Teenagers' Perception of Public spaces and their Practices in ICTs Uses. In C.S. Costa, E. Suklje, T. Kenna et al. (Eds.), Cyber Parks- The interface between people, places and technology (pp. 109-119). Springer.

Menendez, C. (2017, August 8). How to Build More Connected \& Inclusive cities. Meeting of the Mind.

Moffit, S. (2018). The merging of 30 technologies what will impact us the most over the next decade. Wikibrands. Retrieved from Wiki-brands.com/the-merging-30-technologies-what-will-impact-us-the-most-over-the-next-decade/

OECD. (2017). Key Issues for the Digital Transformation of the G-20.

Peppet, S. R. (2014). Regulating the internet of things: First steps towards managing discrimination, privacy, security and consent. Texas Law Review, 93, 85-176.

Robinson, L., Cotton, S.R., Ono, H., Quan-Haase, A., Mesch, G., Chen, W., Schultz, J., ... Stern, M.J. (2015). Digital Inequalities and Why They Matter. Information, Communication \& Society, 18(5), 569-582. $10.1080 / 39118 x .2015 .1012532$ 
Royakkers, L., Jelte, T., Kool, L., \& Van Est, R. (2018). Societal and ethical issues of digitization. Ethics and Information Technology, 20(2), 127-142. doi:10.1007/s10676-018-9452-x

Skrzauskiene, A., Tanosiunaiute, R., \& Zaleniene, I. (2013). Defining Social Technologies. In Proceedings of the $4^{\text {th }}$ International Conference on IS Management and Evaluation: ICIME. Academic Conference Limited.

Slash Team. (2018). UI/UX.

Smart Cities Connect. (2018). City spotlights: citizen Life \& Governance.

United Nation Human Settlements Program. (2012). State of the World's Cities 2012/2013. Nairobi, Kenya: UN-HABITAT. Retrieved from http://www.unhabitat.org/pmss/listtemDetails.aspx?publication=3387

Vorhauser-Smith. S. (2017). Humanizing Technology - Art Meets Science. Hakisa.

Weinstein, Z. (2007), Digital Gap in Project Renewal of Disadvantaged Neighborhoods. IT magazine, 37. (In Hebrew).

Weinstein, Z. (2017). Digi-Tel- Bespoke Technology for Connected City of Tel Aviv. In C. Certoma, M. Dyer, L. Pocatilu, \& F. Rizzi (Eds.), Citizen Empowerment and Innovation in the Data-Rich World (pp. 159-176). Switzerland: Springer. doi:10.1007/978-3-319-47904-0_10 


\section{KEY TERMS DEFINITION}

Humanizing technology: The creators of technology are the people themselves. Therefore, interrelation attitudes should be among them. By humanizing technology, we mean the way technology is invited, used and adapted to human needs in various features.

Smart city: There is no "smart city". It is technology that enables a city to become "smart". Smart city is an attractive place which creates, thinks, participates, shares, and flexibly, adaptably and efficiently serves its residents.

Innovation: A way of thinking and observing problems and issues differently by using technological means to encourage creativity and thinking out of the box for the benefit of people, development processes and advancements in all fields of life.

Spatial digitization: Digital infrastructures such as IOT, GIS and WI-FI that provide outcomes of collected data analysis for city citizens in a convenient updated and quick manner.

Zvi Weinstein is the CO-Founder of the Israel Smart Cities Institute. He teaches at the Tel Aviv University the Urban Design Lab and lead a research on Spatial Poverty in Israel and Project Renewal as the case study. During the years 1978-2015 he served as the National Coordinator of Project Renewal of Disadvantaged Neighborhoods at the Israeli Ministry of Construction and Housing dealing with multi-disciplinary issues of physical, social, economic, developing of community services, educational, health and employment. He holds a PHD in Urban Regeneration, MSc. In Town Planning, MA in Public Policy, School of Education, LLM in Law. Zvi Weinstein represents Israel in four Scientific Committees in the EU - People Friendly City in a Data Rich World; Cyberparks; Citizen Science, and Rethinking the Built Environment. He runs two personal initiatives for the last 14 years: Vocational training for young people living in distressed neighborhoods and contributing computers for families with children in poor neighborhoods as a mean to limit the digital gap. He participates in international conferences as well as speaker to Smart City Expo Barcelona for the last six years and publishes papers in the international magazines. 